\title{
SILYLATIONS OF SOME POLYHALOGENATED COMPOUNDS
}

\author{
David Ballard, Thomas Brennan, F. W. G. Fearon, Kyo Shinna, Ionel \\ Haiduc, and Henry Gilman
}

Department of Chemistry, Iowa State University, Ames, Iowa 50010 U.S.A.

\section{INTRODUCTION}

The search for thermally stable polymers has led to an expanding study of organosilicon compounds. Among the most promising types seem to be those including polyhalogenated aromatic nuclei linked to the organosilicon moieties. In an effort to obtain monomeric model compounds of various structures, whose chemical and physical properties could suggest new routes to polymers of the types mentioned above and would permit a priori evaluation of the properties of such polymers, an extensive investigation of the silylation of polyhalogenated organic compounds was initiated in this laboratory. The results were rewarding, especially in the sense that several unusual and unexpected reactions were found.

Two main approaches for the silylation of polyhalogenated compounds were considered: (a) the direct reaction of polyhalogenated compounds with lithium or magnesium and chlorotrimethylsilane or other chlorosilanes; and (b) metalation or halogen-metal exchange between the halogenated aromatic compounds and organolithium reagents, followed by derivatization with chlorotrimethylsilane and other chlorosilanes.

It was found that the first approach, (a), gave polysilylated compounds (via Wurtz-Fittig type couplings) only when a haloaromatic compound was treated with stoichiometric amount or a slight excess of lithium (or magnesium) and chlorotrimethylsilane. When attempts were made to force the silylation, in order to obtain highly silylated derivatives by reacting polyhaloaromatic compounds with a large excess (ten to twenty fold) of lithium and chlorotrimethylsilane, an unusual formation of tetrakis(trimethylsilyl)allene was observed with the cleavage of the aromatic ring. This happened when the aromatic parent compound contained at least four halogen atoms and/or some trimethylsilyl substituents on the ring. With $p$-dihalobenzenes reductive silylation occurred under similar conditions, with the formation of cyclohexadiene derivatives. Aliphatic polyhalogenated compounds, with an excess of lithium (or magnesium) and chlorotrimethylsilane, also gave tetrakis(trimethylsilyl)allene, but mono- and di-acetylenes were obtained in certain cases.

The second approach, (b), afforded the synthesis of polysilylated halobenzenes without difficulty. In connection with these studies selective action of certain organolithium reagents was observed, as well as simultaneous halogen-metal and hydrogen-metal interconversions in a polyhalogenated benzene. 
A detailed presentation of these results will follow, the emphasis being upon the unusual formation of the tetrakis(trimethylsilyl)allene, in many of the reactions investigated.

The literature prior to our investigations has been relatively abundant in studies of silicon-containing unsaturated systems of both olefinic and acetyllenic types ${ }^{1-3}$; however, only a few allenic systems $(>\mathrm{C}=\mathrm{C}=\mathrm{C}\langle$ ) have so far been described containing organosilicon groups. These carbon-functional organosilicon compounds have been prepared by a variety of routes, mainly by the use of organometallic compounds, but also by direct synthesis, silicon hydride addition reactions and by dehydrogenation of halogenoalkyl-silicon compounds ${ }^{1-3}$; however, it is largely with organometallic reactions that we concern ourselves in this study.

Tetravinylsilane has been prepared from the reaction of vinylmagnesium chloride and silicon tetrachloride ${ }^{4}$; and diphenylethynyldiphenylsilane has been obtained from phenylethynyllithium and dichlorodiphenylsilane ${ }^{5}$. In marked contrast to the large number of such compounds synthesized, compounds containing two or more silicon atoms in an unsaturated system are relatively few. Bis(trimethylsilyl)acetylene has been prepared by conventional organometallic methods ${ }^{6,7}$ and also by an in situ Grignard synthesis, from tetrabromoethylene ${ }^{8}$ :

$$
\mathrm{Br}_{2} \mathrm{C}=\mathrm{CBr}_{2}+\mathrm{Mg}+\mathrm{Me}_{3} \mathrm{SiCl} \rightarrow \mathrm{Me}_{3} \mathrm{SiC} \equiv \mathrm{CSiMe}_{3} \quad(60 \%)
$$

Bis(trimethylsilyl)butadiyne has been prepared in a two-stage reaction from ethynylmagnesium bromide and chlorotrimethylsilane and then oxidative coupling of the product, trimethylsilylacetylene, by cuprous chloride ${ }^{9}$; the Grignard reagent of diacetylene was also used in similar syntheses ${ }^{10,} 11$.

$$
\begin{gathered}
\mathrm{HC} \equiv \mathrm{CMgBr}+\mathrm{Me}_{3} \mathrm{SiCl} \rightarrow \mathrm{HC} \equiv \mathrm{C}-\mathrm{SiMe}_{3} \\
\mathrm{XMgC} \equiv \mathrm{C}-\mathrm{C} \equiv \mathrm{CMgX}+2 \mathrm{Me}_{3} \mathrm{SiCl} \rightarrow \mathrm{Me}_{3} \mathrm{Si}-\mathrm{C} \equiv \mathrm{C}-\mathrm{C} \equiv \mathrm{C}-\mathrm{SiMe}_{3}
\end{gathered}
$$

Only a few silicon-substituted allenes have so far been described. Tetrakis(trichlorosilyl)allene has been prepared by the reaction of carbon tetrachloride with a copper-silicon alloy ${ }^{12}$, while some arylsilicon allenes have been obtained by indirect reactions of triphenylsilyllithium with 1-bromopropene $^{13}$. Tetrakis(trimethylsilyl)allene has been prepared from the interaction of propyne and butyllithium followed by treatment with chlorotrimethylsilane; tris(trimethylsilyl)propyne was also produced in this reaction. It was assumed that the propyne initially reacts with the $n$-butyllithium to give tetralithiopropyne together with some trilithiopropyne ${ }^{14}$;

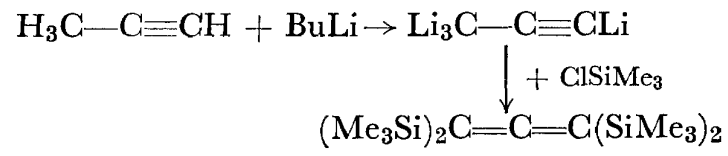

More recent work ${ }^{15}$ suggests that what is thought to be tetralithiopropyne may be tetralithioallene, on the basis of infrared spectra. In this case the alkyne-allene rearrangement takes place during metalation of the propyne: 


$$
\begin{aligned}
& \mathrm{H}_{3} \mathrm{C}-\mathrm{C} \equiv \mathrm{CH} \stackrel{\mathrm{BuLi}}{\longrightarrow} \mathrm{Li}_{2} \mathrm{C}=\mathrm{C}=\mathrm{CLi}_{2} \stackrel{\mathrm{Me}_{3} \mathrm{SiCl}}{\longrightarrow} \\
& \left(\mathrm{Me}_{3} \mathrm{Si}\right)_{2} \mathrm{C}=\mathrm{C}=\mathrm{C}\left(\mathrm{SiMe}_{3}\right)_{2}
\end{aligned}
$$

Only a few organometallic reactions of polyhalo-compounds have been investigated so far. Thus, good yields of poly(trimethylsilyl)methanes have been obtained from an in situ organolithium reaction, using chlorotrimethylsilane, polyhalogenomethanes and lithium in refluxing tetrahydrofuran 8,16 .

$$
\mathrm{CCl}_{4}+8 \mathrm{Li}+4 \mathrm{ClSiMe}_{3} \rightarrow \mathrm{C}\left(\mathrm{SiMe}_{3}\right)_{4}+8 \mathrm{LiCl}
$$

The metallation of pentachlorobenzene ${ }^{17}$, and 1,2,4,5-tetrachlorobenzene $^{17}$ with $n$-butyllithium to give pentachlorophenyllithium, 1,2,4,5tetrachloro-3-lithio- and 1,2,4,5-tetrachloro-3,6-dilithiobenzenes; and the preparation of pentafluorophenyllithium by metalation of pentafluorobenzene ${ }^{18}$, as well as a similar metallation of $1,2,3,4$-tetrafluoro- and 1,2,4,5tetrafluoro-benzenes ${ }^{18}$, afforded some versatile polyhaloaromatic organolithium reagents. These are very useful as intermediates in the synthesis of polysilylated haloaromatic derivatives, and were largely explored in this laboratory ${ }^{19-29}$.

\section{POLYSILYLATIONS OF SOME HIGHLY HALOGENATED AROMATIC COMPOUNDS}

\section{(i) Reactions producing tetrakis(trimethylsilyl)allene}

We have recently reported $30,31,32$ that interaction of several polyhalogenobenzenes with lithium and chlorotrimethylsilane in tetrahydrofuran (THF) gives rise to tetrakis(trimethylsilyl)allene (I) in yields of up to 52 per cent. A general procedure for this type of reaction is as follows. Addition of lithium ( $20 \mathrm{~g}$ atoms) in small amounts at a time, to a vigorously stirred mixture of hexachlorobenzene $(1 \mathrm{~mole})$ and chlorotrimethylsilane (10 moles) in THF leads to an exothermic reaction with precipitation of lithium chloride and rapid darkening of the system. At the termination of the reaction the products are treated with dilute hydrochloric acid and the organic material extracted with ether and distilled to give tetrakis(trimethylsilyl)allene in 27.8 per cent yield, assuming the reaction:

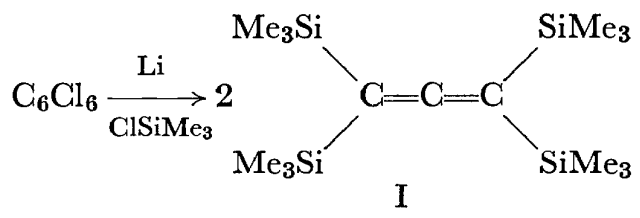

The choice of solvent appears to have a marked effect on the yield of $(\mathbf{I})$. When the above reaction was repeated in 1,2-dimethoxyethane, it proceeded at a slower rate but a 31 per cent yield of (I) was obtained after forty-eight hours. None of (I) was obtained using diethyl ether or a THF/furan (1:1) mixture as solvents. It was thought that changing the metal would have a substantial effect on the course of the reaction and this was found to be true. Interaction of hexachlorobenzene, chlorotrimethylsilane and magnesium in THF under similar conditions to those described above gave no (I), 
although a rapid exothermic reaction occurred with consumption of the hexachlorobenzene after about thirty-six hours; vapour phase chromatography showed the presence of at least twelve components in the reaction mixture. In a similar reaction using sodium instead of magnesium no significant amount of allene (I) was obtained, and 38 per cent of unreacted hexachlorobenzene remained after twenty-four hours of vigorous stirring. Related experiments were carried out using other perhalogenated benzenes. Hexabromobenzene reacted similarly to hexachlorobenzene with excess lithium and chlorotrimethylsilane in $\mathrm{THF}$, giving (I) in a prompt reaction. However, hexakis(dimethylsilyl)benzene, (II), was obtained ${ }^{32}$ in a 27 per cent yield from magnesium, chlorodimethylsilane and hexabromobenzene in THF. From the corresponding reaction of hexabromobenzene with

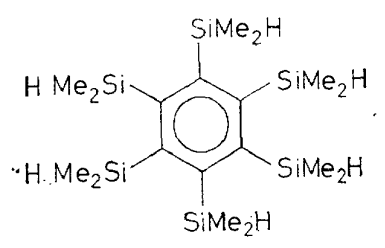

(II)

chlorotrimethylsilane and magnesium a small amount of a compound shown to be $1,1,3,4,6,6$-hexakis(trimethylsilyl)-1,2,4,5-hexatetraene (III), was obtained $^{32}$ :

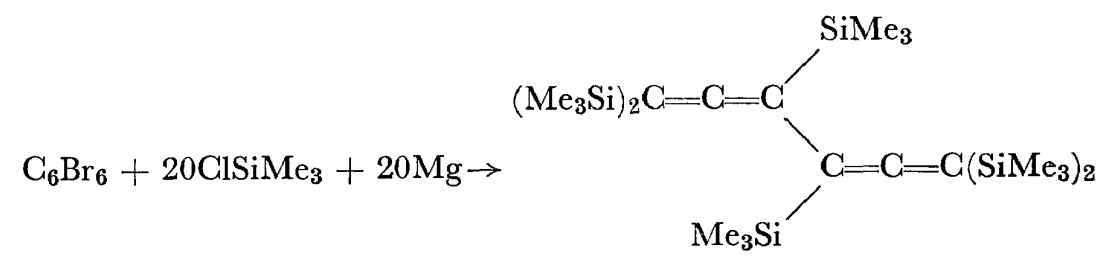

This compound was also produced in low yield from 1,4-bis(trimethylsilyl)tetrachlorobenzene, 1,4-dichlorotetrabromobenzene and hexachlorobenzene with lithium and chlorotrimethylsilane. It has also been made more recently in fairly good yield starting with an aliphatic system (see later). It could be one of the reaction intermediates in the formation of $(I)$ as experiments have shown it to be converted by lithium and chlorotrimethylsilane to the allene (I).

Several other polyhalogenated aromatic compounds have been subjected to similar in situ conditions, in an attempt to learn something of the reaction scheme and also to prepare (I) in higher yields. Using 1,4-bis(trimethylsilyl) tetrachlorobenzene a 52 per cent yield of (I) was obtained. For brevity the results are summarized in Table 1 . 
Table 1. Production of tetrakis(trimethylsilyl)allene (I) from in situ reactions of polyhalobenzenes, lithium and chlorotrimethylsilane

\begin{tabular}{|c|c|c|c|}
\hline $\begin{array}{l}\text { Polyhalogeno } \\
\text { compound }\end{array}$ & Solvent & $\begin{array}{c}\text { Yield of }(\mathrm{I}) \\
\%\end{array}$ & $\begin{array}{c}\text { Other } \\
\text { Products } \%\end{array}$ \\
\hline $\begin{array}{l}\mathrm{C}_{6} \mathrm{Cl}_{6} \\
\mathrm{C}_{6} \mathrm{Cl}_{6} \\
\mathrm{C}_{6} \mathrm{Cl}_{6} \\
\mathrm{C}_{6} \mathrm{Cl}_{5} \mathrm{SiMe}_{3} \\
p-\mathrm{Me}_{3} \mathrm{SiC}_{6} \mathrm{Cl}_{4} \mathrm{SiMe}_{3} \\
\mathrm{C}_{6} \mathrm{Cl}_{5} \mathrm{H} \\
p-\mathrm{HC}_{6} \mathrm{Cl}_{4} \mathrm{H} \\
\mathrm{C}_{6} \mathrm{~F}_{6} \\
\mathrm{C}_{6} \mathrm{~F}_{5} \mathrm{Cl} \\
\mathrm{C}_{6} \mathrm{~F}_{5} \mathrm{Cl} \\
\mathrm{C}_{6} \mathrm{~F}_{5} \mathrm{Br} \\
\mathrm{C}_{6} \mathrm{~F}_{5} \mathrm{SiMe}_{3} \\
p-\mathrm{Me}_{3} \mathrm{SiC}_{6} \mathrm{~F}_{4} \mathrm{SiMe}_{3} \\
\mathrm{C}_{6} \mathrm{Br}_{6} \\
\mathrm{C}_{10} \mathrm{Cl}_{8} \\
1,3,5-\mathrm{C}_{6} \mathrm{Cl}_{3}\left(\mathrm{SiMe}_{3}\right)_{3} \\
\left(\mathrm{C}_{6} \mathrm{Cl}_{5} \mathrm{SiMe}_{2}\right)_{2} \mathrm{O} \\
p-\mathrm{BrC}_{6} \mathrm{Cl}_{4} \mathrm{Br} \\
o-\mathrm{C}_{6} \mathrm{Cl}_{4} \mathrm{H}_{2} \\
p-\mathrm{C}_{6} \mathrm{Cl}_{2} \mathrm{Br}_{4} \\
p-\mathrm{C}_{6} \mathrm{Br}_{4} \mathrm{H}_{2} \\
\mathrm{C}_{6} \mathrm{Br}_{5} \mathrm{OH} \\
\mathrm{C}_{6} \mathrm{Cl}_{5} \mathrm{SnMe}_{3}\end{array}$ & $\begin{array}{l}\text { THF } \\
\text { Dimethoxyethane } \\
\text { THFb } \\
\text { THF } \\
\text { THF } \\
\text { THF } \\
\text { THF } \\
\text { THF } \\
\text { THF } \\
\text { THF/furan } \\
\text { THF } \\
\text { THF } \\
\text { THF } \\
\text { THF } \\
\text { THF } \\
\text { THF } \\
\text { THF } \\
\text { THF } \\
\text { THF } \\
\text { THF } \\
\text { THF } \\
\text { THF } \\
\text { THF }\end{array}$ & $\begin{array}{r}38 \\
31 \\
0 \\
37 \\
52 \\
15 \\
5 \\
5 \\
8 \\
0 \\
7 \\
6 \\
11 \\
26 \\
5 \text { e, } \\
\text { g } \\
\text { g } \\
\text { g } \\
\text { g } \\
\text { g } \\
\text { g } \\
\text { g } \\
\text { g }\end{array}$ & \begin{tabular}{ll} 
& \multicolumn{1}{c}{} \\
& \\
$\mathrm{Me}_{3} \mathrm{SiF}^{\mathrm{d}}$ & \\
$\mathrm{Me}_{3} \mathrm{SiC}_{6} \mathrm{~F}_{5}$ & (7) \\
$\mathrm{Me}_{3} \mathrm{SiF}$ & $\mathrm{SiF}$ \\
$\mathrm{Me}_{3} \mathrm{SiF}$ & \\
$\mathrm{Me}_{3} \mathrm{SiF}$ &
\end{tabular} \\
\hline
\end{tabular}

aIn many reactions hexamethyldisilane was isolated as a by-product.

bMetal used was magnesium.

cAlso obtained 1, 2, 4, 5-tetrakis (trimethylsilyl) benzene $(3 \cdot 7 \%$ ).

dQuantity of fluorotrimethylsilane not determined.

eOctachloronaphthalene gave many products (unidentified)

PWork by A. E. Jukes.

gNot isolated; identified only by v.p.c. and infrared spectra.

\section{(ii) Reductive polysilylation reactions}

When compounds containing only two halogen atoms on the aromatic nucleus, such as $p$-dichloro- and $p$-dibromobenzene (as well as $p$-bis (trimethylsilyl)-benzene) were subjected to the action of a liberal excess of lithium and chlorotrimethylsilane in THF, no allene (I) was formed. Instead, extensive reduction occurred, to give a 44 per cent yield of $1,3,4,6-$ tetrakis(trimethylsilyl)cyclohexa-1,4-diene (VI). In addition, $2 \cdot 7$ per cent of 3,3,6,6-tetrakis(trimethylsilyl)cyclohexa-1,4-diene (VII) was also form$\mathrm{ed}^{33,34}$ :<smiles>[X]c1ccc([X])cc1</smiles>

$X=F, C l$

$\mathrm{R}=\mathrm{SiMe}_{3}$<smiles>[R]C1=CC([R])C([R])=CC1[R]</smiles>

(VI)<smiles>[R]C1([R])C=CC([R])([R])C=C1</smiles>

(VII) 
There is evidence to suggest that a small amount of 1,4,5,6-tetrakis(trimethylsilyl)cyclohexa-1,3-diene is also formed. A similar reductive trimethylsilylation of benzene, toluene, anisole and naphthalene ${ }^{35}$ has been reported previously. Presumably the mechanism involved in our reaction is similar to these; lithium may add directly to the aromatic nucleus, or give anion radicals by electron transfer. The mechanism is similar to that of reduction with sodium ${ }^{36}$ or lithium ${ }^{37}$ in low molecular weight amines ${ }^{38}$.

\section{(iii) Wurtz-Fittig type condensations}

When polyhalobenzenes were reacted with lithium (or magnesium) metal and chlorotrimethylsilane in stoichiometric amount (or only small excess), again no allene (I) was obtained; coupling products, formed by replacement of chlorine with trimethylsilyl groups, were isolated ${ }^{39}$, as shown in the following example:

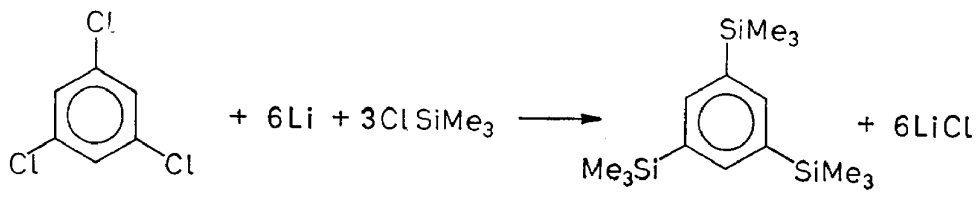

It is interesting to note that in a similar reaction of 1,2,4,5-tetrachlorobenzene, along with 1,2,4,5-tetrakis(trimethylsilyl)benzene (VIII), the allene (I) was also formed:

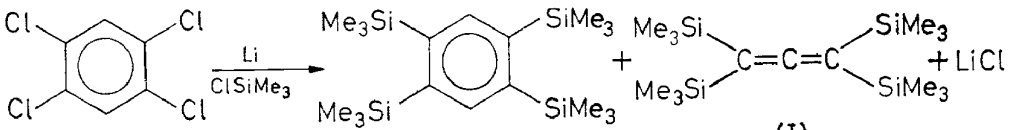

(VIII)

$$
+\mathrm{Me}_{3} \mathrm{SiSiMe}_{3}
$$

This suggests that the presence of at least four halogen atoms in an aromatic molecule is necessary and sufficient for allene formation.

Other examples of coupling reactions are listed in Table 2.

Table 2. Wurtz-Fittig couplings of halobenzenes with chlorotrimethylsilane, lithium or magnesium

\begin{tabular}{|c|c|c|c|c|}
\hline Halobenzene & $\begin{array}{c}\mathbf{L i} \\
\text { (equiv.) }\end{array}$ & $\underset{\text { (equiv.) }}{\mathbf{M g}}$ & $\begin{array}{l}\mathrm{ClSiMe}_{3} \\
\text { (equiv.) }\end{array}$ & $\begin{array}{l}\text { Products isolated } \\
(\% \text { yield })\end{array}$ \\
\hline $\begin{array}{l}\mathrm{C}_{6} \mathrm{H}_{5} \mathrm{Cl} \\
\mathrm{C}_{6} \mathrm{H}_{5} \mathrm{Cl} \\
\mathrm{C}_{6} \mathrm{H}_{5} \mathrm{Cl} \\
p-\mathrm{C}_{6} \mathrm{H}_{4} \mathrm{Cl}_{2} \\
p-\mathrm{C}_{6} \mathrm{H}_{4} \mathrm{Cl}_{2} \\
p-\mathrm{C}_{6} \mathrm{H}_{4} \mathrm{Cl}_{2} \\
o-\mathrm{C}_{6} \mathrm{H}_{4} \mathrm{Cl}_{2} \\
1,3,5-\mathrm{C}_{6} \mathrm{H}_{3} \mathrm{Cl}_{3} \\
\mathrm{i}, 3,5-\mathrm{C}_{6} \mathrm{H}_{3} \mathrm{Cl}_{3} \\
1,2,4,5-\mathrm{C}_{6} \mathrm{Cl}_{4} \mathrm{H}_{2} \\
1,2,4,5-\mathrm{C}_{6} \mathrm{Cl}_{4} \mathrm{H}_{2}\end{array}$ & $\begin{array}{l}\frac{1 \cdot 5}{6} \\
\frac{11}{6} \\
\frac{9}{12} \\
\frac{-}{-}\end{array}$ & $\begin{array}{l}\overline{-} \\
\frac{2}{3} \\
\frac{1}{-} \\
\frac{6}{10}\end{array}$ & $\begin{array}{r}2 \cdot 5 \\
10 \\
2 \\
4 \\
3 \\
1 \\
3 \\
9 \\
12 \\
6 \\
6\end{array}$ & $\begin{array}{l}\mathrm{PhSiMe}_{3}(61) \\
1,4-\mathrm{Me}_{3} \mathrm{Si}_{-} \mathrm{C}_{6} \mathrm{H}_{4} \mathrm{SiMe}_{3}(3 \cdot 6) \\
\mathrm{PhSiMe}_{3}(76 \cdot 7) \\
1,4-\mathrm{Me}_{3} \mathrm{Si}_{-} \mathrm{C}_{6} \mathrm{H}_{4}-\mathrm{SiMe}_{3}(49 \cdot 1) \\
1,4-\mathrm{Me}_{3} \mathrm{Si}_{6} \mathrm{C}_{6} \mathrm{H}_{4}-\mathrm{SiMe}_{3}(84 \cdot 4) \\
1-\mathrm{Cl}_{-}-\mathrm{Me}_{3} \mathrm{SiC}_{6} \mathrm{H}_{4}(33 \cdot 8) \\
1,2-\mathrm{C}_{6} \mathrm{H}_{4}\left(\mathrm{SiMe}_{3}\right)_{2}(26) \\
1,3,5-\mathrm{C}_{6} \mathrm{H}_{3}\left(\mathrm{SiMe}_{3}\right)_{3}(61 \cdot 9) \\
1,3,5-\mathrm{C}_{6} \mathrm{H}_{3}\left(\mathrm{SiMe}_{3}\right)_{3}(74) \\
1,2,4,5-\mathrm{C}_{6} \mathrm{H}_{2}\left(\mathrm{SiMe}_{3}\right)_{4}(4 \cdot 6) \\
1,4-\mathrm{Cl}_{2}-2,5-\left(\mathrm{SiMe}_{3}\right)_{2} \mathrm{C}_{6} \mathrm{H}_{2}(7 \cdot 2)\end{array}$ \\
\hline
\end{tabular}




\section{Discussion}

The formation of the allene (I) by the reaction of polyhalobenzenes with a liberal excess of lithium and chlorotrimethylsilane is a rather unusual reaction. The mechanism by which $(\mathbf{I})$ is formed is likely to be complex, occurring as it does in a heterogeneous system. The production of (I) may be the result of several reaction patterns each proceeding along a separate path. A reaction scheme accounting for the formation of $(I)$ must take into account a number of pertinent facts. Compound $(\mathbf{I})$ was formed by cleavage of an aromatic ring, thus suggesting a highly reactive intermediate. It is presumed that one molecule of the aromatic compound gives two molecules of $(\mathbf{I})$. Certainly in the case of 1,4-bis(trimethylsilyl)tetrachlorobenzene this is so, as a $\mathbf{5 2}$ per cent yield has been obtained. Compound $(\mathrm{I})$ is also formed rapidly in these reactions; in the case of trimethylsilylpentachlorobenzene and 1,4-bis (trimethylsilyl)tetrachlorobenzene, the allene (I) was detected within one minute of the commencement of the reaction. In the slower reactions, such as with the polyfluoro-compounds, varying amounts of hexamethyldisilane were formed, probably from a competing reaction between lithium and chlorotrimethylsilane ${ }^{28}$, a factor which may contribute to the lower yields of (I) obtained from polyfluorobenzenes. The choice of solvent also appears critical; use of diethyl ether or furan as solvent or co-solvent suppresses the formation of $(\mathbf{I})$.

In attempting to envisage the mechanism of formation of the allene, the reactions described above under (ii) and (iii) seem to offer indications about some stages of the reactions. Thus, the isolation of the Wurtz-Fittig coupling products from the reactions with stoichiometric amounts of lithium and chlorotrimethylsilane, suggests that the first stage of the reaction is a polytrimethylsilylation of the halobenzene.

From steric considerations, among the most highly trimethylsilylated compounds which can be formed without strain are 1,4-dichloro-tetrakis(trimethylsilyl)benzene (IV) and 1,4-difluoro-tetrakis(trimethylsilyl)benzene (V).

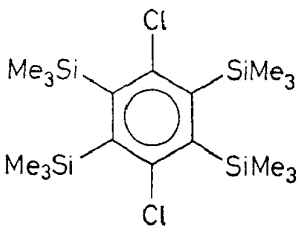

(IV)

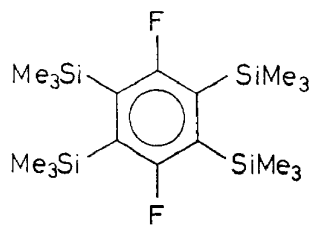

(V)

Stuart-Briegleb molecular models of these compounds can be constructed without difficulty, but they show considerable strain when attempts are made to bring three or more trimethylsilyl groups in vicinal positions. No such compound has been isolated so far, although hexakis(dimethylsilyl)benzene was prepared, as mentioned above. In this compound the less bulky $\mathrm{SiMe}_{2} \mathrm{H}$ groups do not produce significant steric hindrance. Therefore, though compounds (IV) and (V) were not isolated in the reactions which eventually give allene (I), we can consider them as possible intermediates, either as such or their reduced forms (see further). 
The silylation of the haloaromatic nucleus in either Wurtz-Fittig type condensation described above, (iii), or as a stage in the formation of the allene (I), can be interpreted in two ways: (a) formation of a haloaryllithium compound, which reacts further with the chlorosilane; or (b) formation of trimethylsilyllithium which then couples with the haloaromatic nucleus.

The first alternative, (a), is suggested by the formation of pentafluorophenyllithium from bromopentafluorobenzene with lithium amalgam in ether ${ }^{40}$, and by the vigorous reaction of hexachlorobenzene with lithium metal, which in the absence of chlorosilanes gives a polymeric material (probably through the decomposition of pentachlorophenyllithium via benzyne-type intermediates ${ }^{41}$ ). At low temperatures pentachlorophenyllithium is stable and reacts with chlorotrimethylsilane to give pentachlorophenyltrimethylsilane. ${ }^{42}$

The second alternative, (b), which assumes trimethylsilyllithium as an intermediate 28 , involves its possible formation from chlorotrimethylsilane and lithium:

$$
\mathrm{Me}_{3} \mathrm{SiCl}+2 \mathrm{Li} \rightarrow \mathrm{M}_{3} \mathrm{eSiLi}+\mathrm{LiCl}
$$

and the isolation of hexamethyldisilane as a by-product can be explained by the following reaction:

$$
\mathrm{Me}_{3} \mathrm{SiCl}+\mathrm{LiSiMe}_{3} \rightarrow \mathrm{Me}_{3} \mathrm{Si}-\mathrm{SiM}_{3} \mathrm{e}+\mathrm{LiCl}
$$

This assumption finds some support in the recent formation of trimethylsilyllithium, prepared by refluxing bis(trimethylsilyl)mercury with lithium in $\mathrm{THF}^{42 \mathrm{a}}$.

The reaction described above for $p$-dihalobenzenes, (iii), suggests that reductive silylation of the aromatic ring should be also considered as a stage in the formation of the allene ( $\mathrm{I})$. The complete elimination of the halogen from the aromatic molecule or from the cyclohexene derivative formed, would result in the formation of a diradical. This is in accordance with the suggestion $^{43}$ that reactions of organic halides with metals proceed via intermediate formation of a free radical species on the metal surface.

Summing up such considerations, a mechanism of formation of the allene (I) could be described by the following succession of reactions:

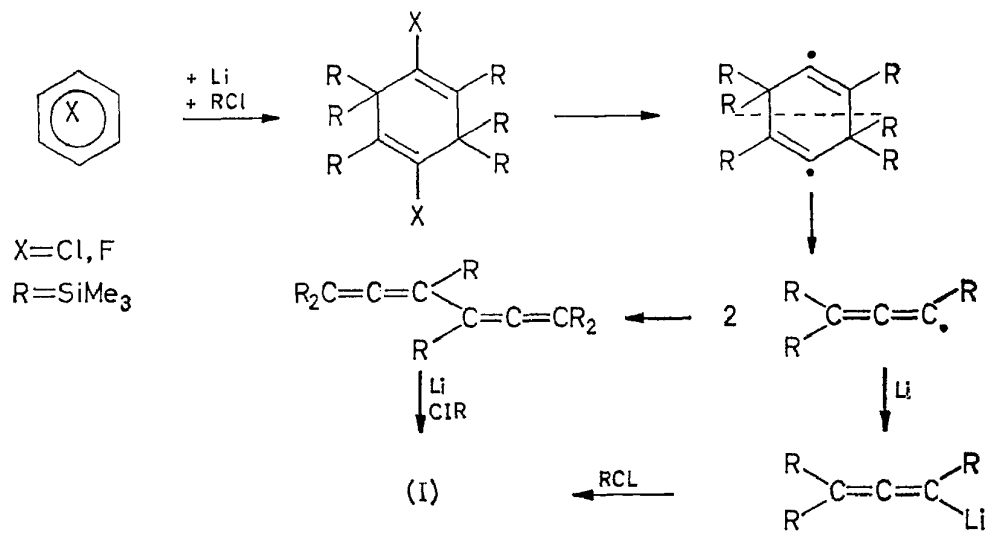


Another hypothetical route for the formation of (I) could be via an anion radical process ${ }^{44}$, in which the electron redistribution results in cleavage of the ring with the formation of two cyclopropane entities:

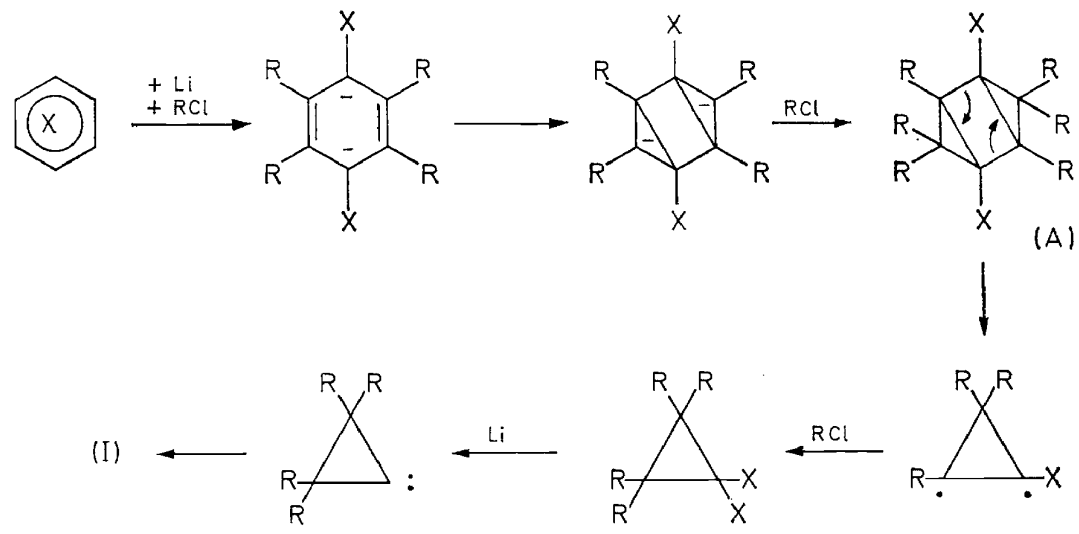

(B)

A part of such a series of reactions finds support in a known facile transformation of dihalocyclopropanes into allene, under the action of organolithium reagents 45,46 .

The observation that $(\mathrm{I})$ is not formed in ether or furan as solvents can be explained by such solvents being less satisfactory for the solvation of the alkali metal cation, and hence the electron transfer from the metal to the aromatic nucleus is too slow to effect the reduction and formation of the intermediate anion radicals.

A reaction pattern can also be envisaged via a benzadiyne intermediate. Assuming the production of 1,4-dilithiotetrahalobenzene, one can expect it to decompose rapidly at the reaction temperature. A possible mechanism could then be the following:

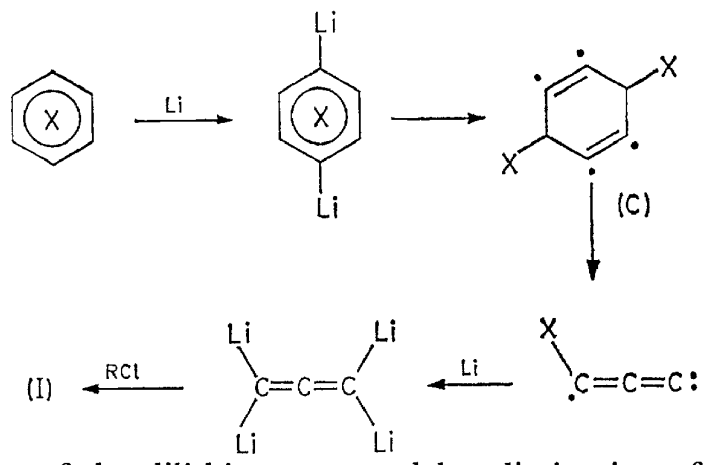

Decomposition of the dilithio compound by elimination of two molecules of lithium chloride can give a benzadiyne type intermediate (C) which could break down to an allenic radical, and further react with chlorotrimethylsilane giving the allene (I). Such a mechanism is suggested by the evidence of formation of related benzadiyne type species from 1,6-difluoro-3,5dibromo- $p$-xylene and 1,4-difluoro-2,5-dibromobenzenewith $n$-butyllithium ${ }^{47}$. 


\section{(iv) Silylation via metallation and/or halogen-metal exchange}

It was reported that hexachlorobenzene when treated with $n$-butyllithium in THF at low temperature undergoes halogen-metal exchange, to give pentachlorophenyllithium ${ }^{42}$, a reagent which was also obtained from pentachlorobenzene by metallation with $n$-butyllithium ${ }^{17}$. Pentachlorophenylmagnesium chloride has been prepared from hexachlorobenzene in the usual manner ${ }^{20}$. These reagents were used for the preparation of trimethylsilylpentachlorobenzene 28,42 Other pentachlorophenyl organosilicon derivatives were prepared by using either the organolithium or Grignard reagent ${ }^{19-22,25,27,29}$. In a similar way, pentafluorophenyllithium prepared by metallation of pentafluorobenzene ${ }^{18}$ was used for the synthesis of several pentafluorophenyl organosilicon derivatives ${ }^{48}$. Other polyhalogenated benzenes were also metallated. Thus, 1,2,4,5-tetrachlorobenzene with $n$-butyllithium gave mono- and dilithio-derivatives ${ }^{17}$ which served as intermediates in the synthesis of mono- and disilylated tetrachlorobenzenes, (IX) 28 and other compounds, such as a disiloxane analogue of paracyclophanes 25,29 .

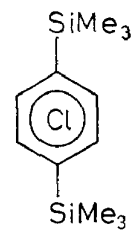

(IX)

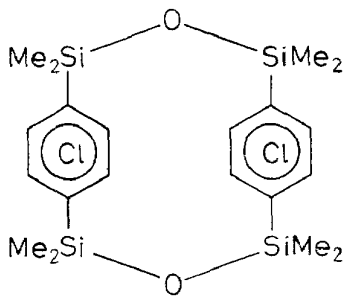

$(\mathrm{X})$

Also, 1,2,4,5-tetrafluorobenzene and 1,2,3,4-tetrafluorobenzene were metallated with $n$-butyllithium 18 and the fluoroaromatic organolithium reagents thus formed were used for the synthesis of several organosilicon derivatives ${ }^{26}$. A similar metallation takes place in the case of 1,3,5-trichlorobenzene ${ }^{49}$ :

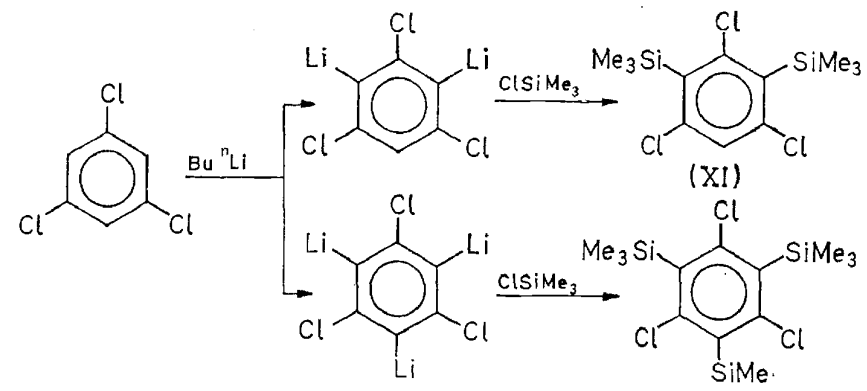

(XII)

In all of the metallations of polychlorobenzenes described above the hydrogen-metal interconversion occurs without considerable involvement of the halogen atoms. Only in few cases, minor chlorine-metal exchange ${ }^{17}$ or coupling of the fluoroaromatic compound with the organolithium reagent ${ }^{24}$ was observed. 
Completely unexpectedly when 1,2,3,4-tetrachlorobenzene was treated with $n$-butyllithium in THF at low temperature, both halogen-metal exchange and metallation occurred, which gave after derivatization with chlorotrimethylsilane a mixture of two silylated polyhalobenzenes; these were separated and identified ${ }^{50}$.

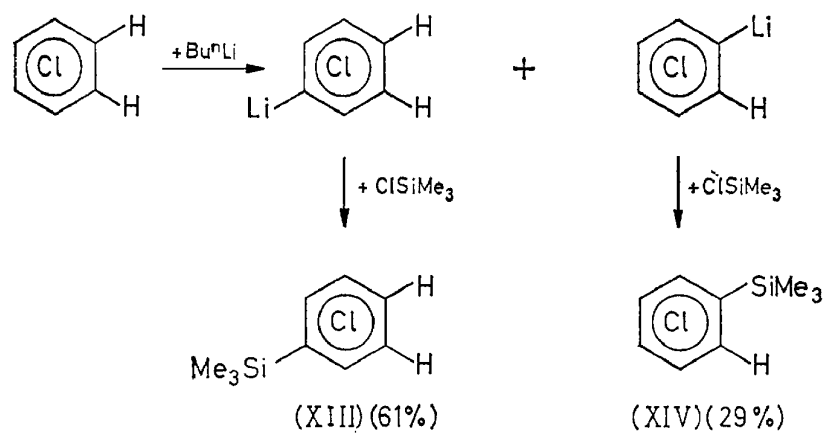

Tetrachlorobenzene treated with two equivalents of $n$-butyllithium undergoes both halogen-metal exchange and metallation in the same molecule ${ }^{50}$ :

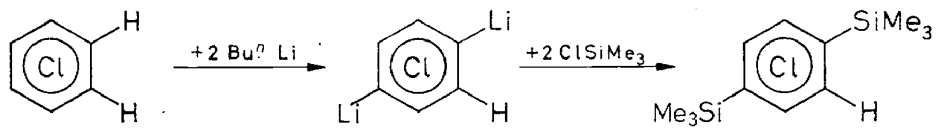

(XV)

It is interesting to note that some organolithium reagents, other than $n$-butyllithium, showed remarkable selectivity in their reactions with $1,2,3,4-$ tetrachlorobenzene. Thus, tert-butyllithium enters into only halogen-metal exchange (with the formation of XIII), while methyllithium and phenyllithium react preferentially (over 95 per cent) via metallation (to give XIV) ${ }^{\mathbf{5 1}}$.

In the reaction of 1,2,3-trichlorobenzene with $n$-butyllithium also both metallation and halogen-metal exchange occurred concurrently50:

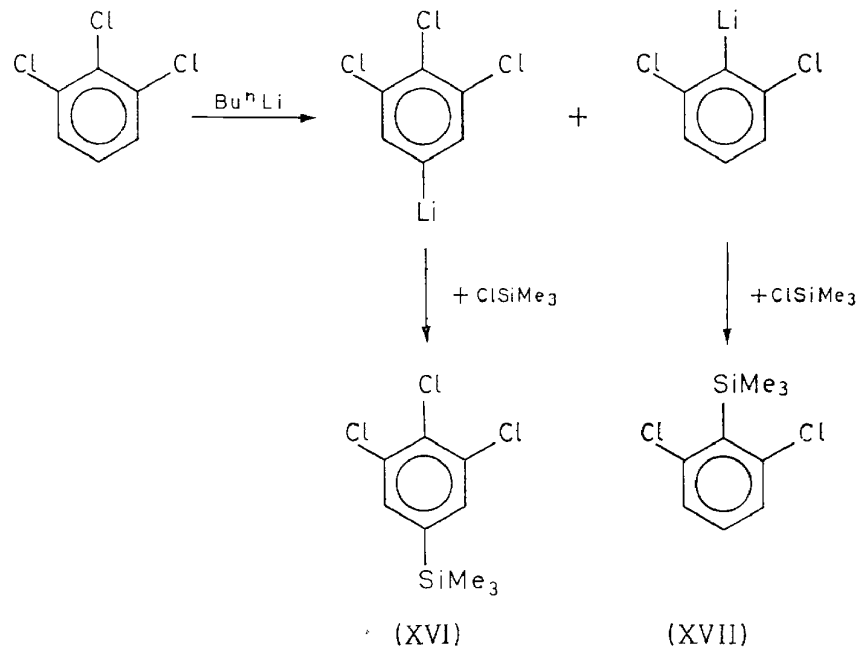


The reactions of other polychlorobenzene isomers with organolithium reagents, followed by derivatization with chloroorganosilanes, are currently being investigated in order to learn more about the reaction pathways and to explore the synthetic possibilities.

\section{POLYSILYLATIONS OF SOME HIGHLY HALOGENATED ALIPHATIC COMPOUNDS}

\section{(i) Reactions producing tetrakis(trimethylsilyl)allene (I)}

As an extension of the novel reactions giving rise to tetrakis(trimethylsilyl)allene (I) similar reactions were attempted using highly halogenated aliphatic compounds, both saturated and unsaturated ${ }^{52}$. Limited research has been done previously in this field ${ }^{8}, 16$, mainly with one and two carbon systems.

We have found that tetrakis(trimethylsilyl)allene (I) is readily obtained from several polychlorinated alkanes and alkenes in reactions with reactive metals and chlorotrimethylsilane. In a typical case, hexachloropropene $(0.1 \mathrm{~mole})$ dissolved in tetrahydrofuran is added slowly to a vigorously stirred mixture of magnesium $(2 \mathrm{~g}$. atoms), chlorotrimethylsilane (1 mole) and tetrahydrofuran at $0^{\circ}$. A vigorous exothermic reaction occurs with separation of magnesium chloride. After subsequent work-up and fractional distillation of the reaction product a 65 per cent yield of (I) is obtained. For other polychlorocarbons the technique is essentially similar. The results are given in Table 3.

Table 3. Production of tetrakis(trimethylsilyl)allene from in situ reactions of polyhalocarbons, metal and chlorotrimethylsilane in THF

\begin{tabular}{|c|c|c|c|}
\hline Compound & $\begin{array}{c}\text { Reaction } \\
\text { temperature } \\
{ }^{\circ} \mathrm{G}\end{array}$ & Metal & $\begin{array}{c}\text { Yield of }(\mathbf{I}) \\
\%\end{array}$ \\
\hline $\begin{array}{l}\mathrm{Cl}_{3} \mathrm{CCCl}=\mathrm{CCl}_{2} \\
\mathrm{Cl}_{3} \mathrm{CCCl}=\mathrm{CCl}_{2} \\
\mathrm{Cl}_{3} \mathrm{CCCl}=\mathrm{CCl}_{2} \\
\mathrm{Cl}_{3} \mathrm{CCCl}=\mathrm{CCl}_{2} \\
\mathrm{Cl}_{3} \mathrm{CCCl}=\mathrm{CCl}_{2} \\
\mathrm{Cl}_{3} \mathrm{CCCl}=\mathrm{CCl}_{2} \\
\mathrm{Cl}_{3} \mathrm{CCCC} \mathrm{CCl}_{3} \\
\mathrm{Cl}_{3} \mathrm{CCCl} \mathrm{CCCl}_{3} \\
\mathrm{Cl}_{2} \mathrm{C}=\mathrm{CCl}-\mathrm{CCl}=\mathrm{CCl}_{2} \\
\mathrm{Cl}_{2} \mathrm{C}=\mathrm{CCl}-\mathrm{CCl}=\mathrm{CGl}-\mathrm{CCl}=\mathrm{CCl}_{2} \\
\mathrm{Cl}_{2} \mathrm{C}=\mathrm{CCl}-\mathrm{CCl}=\mathrm{CCl}-\mathrm{CCl}=\mathrm{CCl}_{2} \\
\mathrm{Cl}_{3} \mathrm{C}-\mathrm{CCl}{ }_{2}-\mathrm{CCl}_{2} \mathrm{H}\end{array}$ & $\begin{array}{r}20 \\
0 \\
20 \\
0 \\
20 \\
20 \\
20 \\
0 \\
20 \\
0 \\
0 \\
20\end{array}$ & $\begin{array}{l}\mathrm{Lia}^{\mathrm{a}} \\
\mathrm{Li} \\
\mathrm{Mg} \\
\mathrm{Mg} \\
\mathrm{Na} \\
\mathrm{Ba} \\
\mathrm{Mg} \\
\mathrm{Mg} \\
\mathrm{Li} \\
\mathrm{Li} \\
\mathrm{Li} \\
\mathrm{Li}\end{array}$ & $\begin{array}{l}40 \\
73 \\
52 \\
65 \\
\text { trace } \\
\text { trace } \\
56 \\
33 \\
5^{\mathrm{b}, \mathrm{c}} \\
61^{\mathrm{d}} \\
37^{\mathrm{c}, \mathrm{d}} \\
37^{\mathrm{e}}\end{array}$ \\
\hline
\end{tabular}

aUsing $\mathrm{Ca}, \mathrm{Be}, \mathrm{Al}, \mathrm{Zn}$, and $\mathrm{Cd}$ none of $(\mathrm{I})$ was obtained.

bSecondary product, using tetrahydro-2-methylfuran as solvent $11 \%$ of (I) was obtained.

$\mathbf{M g}$ gave a different product.

dYields calculated on basis of $1 \mathrm{~mol}$. of the chlorocarbon producing 2 moles of (I).

eNone of (I) was obtained using $\mathrm{Mg}$.

The reaction with hexachloropropene has been studied in greater detail. The effect of using different metals in the reaction is quite marked. Lithium and magnesium react vigorously to give (I) in high yields, usually as the 
only isolable product. The effect of temperature seems an important factor as substantially higher yields are obtained at $0^{\circ}$ than at $20^{\circ}$.

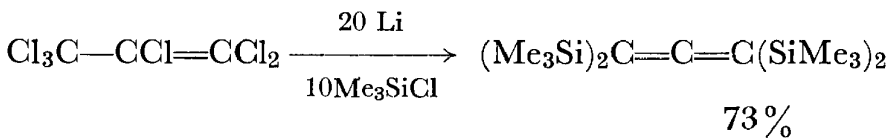

Sodium and barium react slowly with hexachloropropene and $\mathrm{CISiMe}_{3}$ to give a number of products; however, a detectable quantity of (I) is obtained. Less reactive metals (e.g., Ca, Be, Al, Zn, and $\mathrm{Cd}$ ) do not give any (I); however, a reaction does occur and fairly good yields of perchloro(3,4-dimethylene) cyclobutene (XVIII) are obtained;

$$
2 \mathrm{Cl}_{3} \mathrm{C}-\mathrm{CCl}=\mathrm{CCl}_{2} \frac{20 \mathrm{Al}}{\left(10 \mathrm{Me}_{3} \mathrm{SiCl}\right)}
$$<smiles>ClC(Cl)=C=C1C(Cl)=C(Cl)C1=C(Cl)Cl</smiles>

(XVIII)

a compound which has been obtained in 44 per cent yield from aluminium and hexachloropropene in the absence of chlorotrimethylsilane in THF. It has also been prepared in a similar synthesis but using ether as solvent ${ }^{53}$.

It appears, too, that the choice of solvent has a marked effect of the course of reaction and yield of (I) (Table 4).

Table 4. Interaction of magnesium, hexachloropropene and chlorotrimethylsilane using various solvents $\left(\right.$ at $20^{\circ}$ )

\begin{tabular}{l|c}
\hline \multicolumn{1}{c|}{ Solvent } & $\begin{array}{c}\text { Yield of }(\mathrm{I}) \\
\%\end{array}$ \\
\hline Tetrahydrofuran & 52 \\
Tetrahydro-2-methyl-furan & 23 \\
1,2-Dimethoxyethane & 15 \\
Tetrahydropyran & 10 \\
Diethyl ether & 0 \\
1,4-Dioxan & 0 \\
2,2,4,4-Tetramethyltetrahydrofuran & 0 \\
\end{tabular}

In an effort to learn more of the reaction pattern, hexachloropropene was reacted with lithium (or magnesium) in THF at $20^{\circ}$ and the chlorotrimethylsilane was added only after the exothermic reaction had ceased and the excess metal was separated; subsequent work up failed to give any of (I) and only a black carbonaceous-like material was obtained.

A number of reaction schemes can be proposed to explain the production of $(I)$. It does seem, however, that the first stage of the reaction involves reduction of the hexachloropropene by lithium; whether this gives an allene (A) or an acetylene (B) is uncertain.<smiles>ClC(Cl)(Cl)C(Cl)(Cl)Cl</smiles> 
Acetylene-allene isomerisations are well known and (A) could also be formed from (B) by isomerisation. Tetrachloroallene (A) is unstable at room temperatures $^{54}$ and immediately dimerises; reaction of this dimer with lithium could give rise to XVIII55.

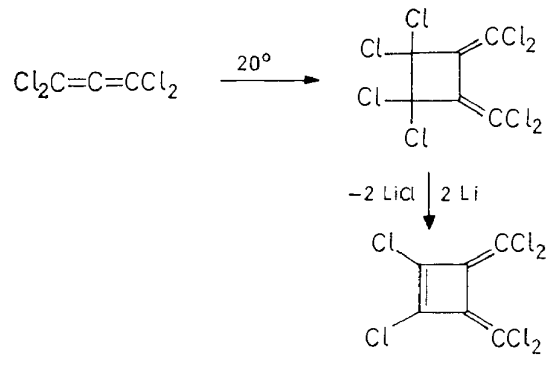

(XVIII)

As mentioned above, it is conceivable that attack of lithium on chlorotrimethylsilane might give rise to the very reactive trimethylsilyllithium as an intermediate. This could then react immediately with either tetrachloroallene (A) or tetrachloropropyne (B) to give the allene (I).

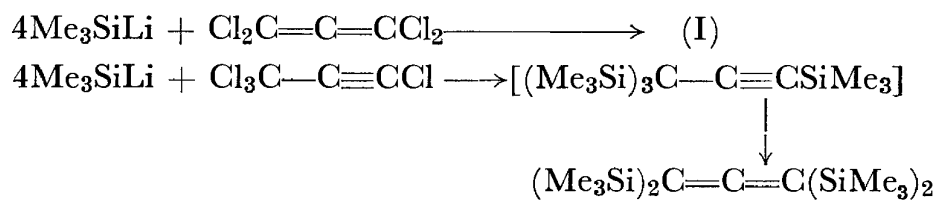

(I)

A related intermediate, tris(trimethylsilyl)propyne, was isolated from the reaction of trilithiopropyne and chlorotrimethylsilane and rearranged to an allene when subjected to photolysis or pyrolysis ${ }^{14}$.

$$
\begin{aligned}
\mathrm{C}_{3} \mathrm{Li}_{3} \mathrm{H} \stackrel{\mathrm{ClSiMe}_{3}}{\longrightarrow}\left(\mathrm{Me}_{3} \mathrm{Si}\right)_{2} \mathrm{CH}-\mathrm{C} \equiv & \mathrm{CSSiMe}_{3} \rightarrow \\
& \left(\mathrm{Me}_{3} \mathrm{Si}\right)_{2} \mathrm{C}=\mathrm{C}=\mathrm{CHSiMe}_{3}
\end{aligned}
$$

Another possible reaction scheme assumes replacement of all chlorine atoms in (A) and (B) by lithium, thereby giving tetralithioallene and tetralithiopropyne, respectively, which can then react with chlorotrimethylsilane to give (I). Similar postulates can be presented for the formation of (I) from magnesium, chlorotrimethylsilane and hexachloropropene. A WurtzFittig coupling reaction could explain the formation of $(\mathbf{I})$ from tetrachloroallene (A) or tetrachloropropyne (B), but the intermediate formation of poly-Grignard reagents cannot be completely ruled out.

Tetrakis(trimethylsilyl)allene (I) was also obtained in good yields from octachloropropane, magnesium and chlorotrimethylsilane. Magnesium may reduce the saturated chlorocarbon, perhaps via hexachloropropene, to $(\mathrm{A})$ or $(\mathrm{B})$, which react in the manner indicated previously.

The reaction of decachlorohexa-1,5-diene (synthesized from hexachloropropene and copper bronze in a selective reduction ${ }^{56}$ ) with lithium or magnesium and chlorotrimethylsilane gave interesting results. Using 
magnesium, a 28 per cent yield of 1,1,3,4,5,6-hexakis(trimethylsilyl)-1,2,4,5hexatetraene (III) was produced, whereas with lithium a 37 per cent yield of the allene (I) resulted. The reaction can be understood as a reduction of the perchlorodiene with magnesium to give allenic or acetylenic species

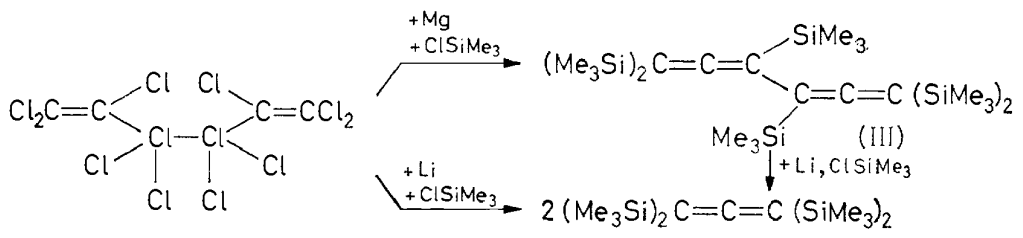

(in a similar manner to that obtained with hexachloropropene) and subsequent trimethylsilylation with the formation of the "biallene" (III). The formation of the allene (I) using lithium is not surprising since it has been shown that the tetraene (III) is easily converted by lithium and chlorotrimethylsilane in THF to (I).

Selective reduction of the decachlorohexa-1,5-diene with alcoholic potassium hydroxide gave good yields of octachlorohexa-1,3,5-triene ${ }^{57}$, and this compound, on treatment with lithium and chlorotrimethylsilane at $0^{\circ}$, gave a 61 per cent yield of the allene (I). Production of (I) from the triene would require the rupture of a double bond; obviously an extensive rearrangement occurs. Such rearrangements are not unknown as was demonstrated by the formation of $(\mathrm{I})$ as a secondary product in similar reactions with hexachlorobuta-1,3-diene. As a 61 per cent yield of (I) was obtained, it is concluded that one mole of the triene gives two moles of the allene (I). Perhaps the reaction proceeds by some trimethylsilylation until steric factors become important and a rearrangement to a 2,4-diyne gives a structure more easily cleaved at the 3 -position by lithium and chlorotrimethylsilane:

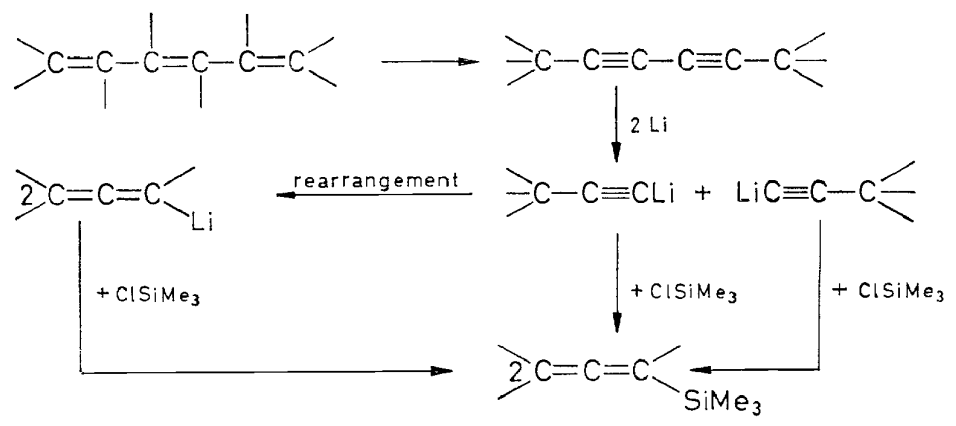

Alternatively, rearrangement of a 2,4-diyne backbone to a 1,2,4,5-tetraene can be considered, and this compound is cleaved by lithium and chlorotrimethylsilane. 

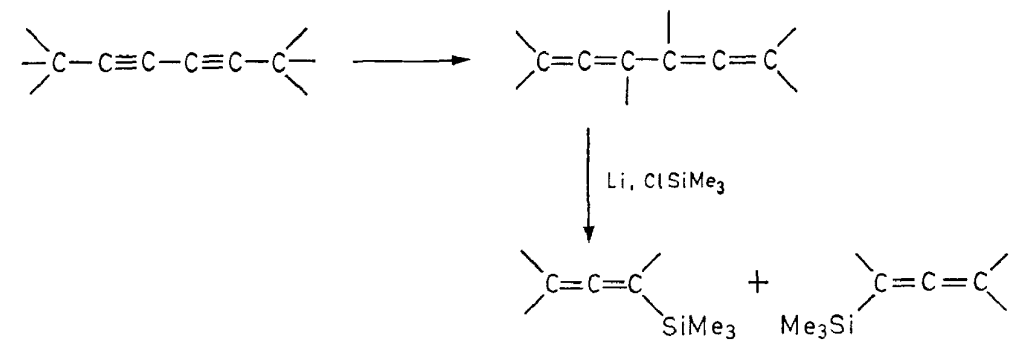

In an extension of these studies with perhalogenated compounds we have treated 1,1,1,2,2,3,3,-heptachloropropane under similar conditions with lithium and magnesium. Magnesium gives a mixture of two compounds, identified as tris(trimethylsilyl)allene and tris(trimethylsilyl)propyne, with none of (I) being obtained; lithium gives a 37 per cent yield of (I), in addition to the compounds obtained with magnesium. A similar interpretation can be put forward for the production of these compounds as for hexachloropropene. However, the non-isolation of (I) with magnesium suggests that the hydrogen atom is not replaced by the metal or Grignard intermediate whereas with lithium such a replacement can occur.

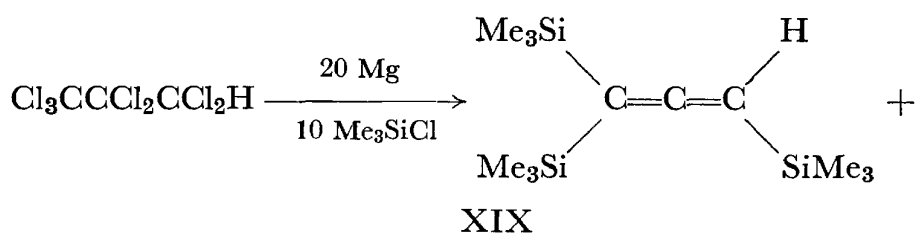

$\left(\mathrm{Me}_{3} \mathrm{Si}\right)_{2} \mathrm{C}-\mathrm{C} \equiv \mathrm{CSiMe}_{3}$

$\mathrm{XX}$

$\mathrm{Cl}_{3} \mathrm{CCCl}_{2} \mathrm{CCl}_{2} \mathrm{H} \underset{10 \mathrm{Me}_{3} \mathrm{SiCl}}{\stackrel{20 \mathrm{Li}}{\longrightarrow} \mathrm{XIX}}+\mathrm{XX}+\mathrm{I}(37 \%)$

\section{(ii) Reactions producing other allenic compounds}

In an effort to produce unsaturated organosilicon compounds with a functional group attached to silicon (e.g., $\mathrm{Si}-\mathrm{H}, \mathrm{Si}-\mathrm{Cl}, \mathrm{Si}-\mathrm{OEt}$ ), and also to learn whether the reaction leading to the allene (I) from hexachloropropene is a general one for the synthesis of silylated allenes, we have reacted organofunctional chlorosilanes with magnesium and hexachloropropene in THF. The results are shown in Table 5. The data obtained suggest that the reaction is a general method for the preparation of polysilylated allenes; the silicon-hydrogen bond does not seem to be appreciably attacked by magnesium under these conditions. 
Table 5. Synthesis of other silylated allenes from magnesium, chlorosilanes and hexachloropropene in $\mathrm{THF}$

\begin{tabular}{l|c|c|c}
\hline \multicolumn{1}{c|}{ Chlorosilane } & $\begin{array}{c}\text { Reaction } \\
\text { temperature }\end{array}$ & Allene produced & $\begin{array}{c}\text { Yield } \\
\%\end{array}$ \\
\hline $\mathrm{Me}_{2} \mathrm{SiHCl}$ & 0 & $\left(\mathrm{HMe} \mathrm{Ci}_{2}\right)_{2} \mathrm{C}=\mathrm{C}=\mathrm{C}\left(\mathrm{SiMe}_{2} \mathrm{H}\right)_{2}$ & 56 \\
$\mathrm{MePhSiHCl}$ & 20 & $(\mathrm{HPhMeSi})_{2} \mathrm{G}=\mathrm{C}=\mathrm{C}(\mathrm{SiMePhH})_{2}$ & 33 \\
$\mathrm{Ph}_{2} \mathrm{SiHCl}$ & 20 & $\left(\mathrm{HPh}_{2} \mathrm{Si}\right)_{2} \mathrm{C}=\mathrm{C}=\mathrm{C}\left(\mathrm{SiPh}_{2} \mathrm{H}\right)_{2}$ & 12 \\
\hline
\end{tabular}

\section{(iii) Reactions producing mainly acetylenic compounds}

Recent literature ${ }^{58}$ has reported the relative inertness of hexachlorobuta1,3-diene. We have reacted hexachlorobutadiene with a number of metals and triorganochlorosilanes in THF under a variety of conditions. The findings have been interesting, giving some rather unexpected products. The results are shown below (Table 6).

Table 6. Interaction of hexachlorobutadiene with metals and chlorotrimethylsilane in THF

\begin{tabular}{|c|c|c|c|c|}
\hline Metal & $\begin{array}{l}\text { Reaction } \\
\text { temperature }\end{array}$ & Product & $\begin{array}{c}\text { Yield } \\
\%\end{array}$ & $\begin{array}{l}\text { Other } \\
\text { products }\end{array}$ \\
\hline $\begin{array}{l}\mathrm{Li} \\
\mathrm{Na}\end{array}$ & $\begin{array}{l}20 \\
20\end{array}$ & $\begin{array}{l}\left(\mathrm{Me}_{3} \mathrm{Si}\right)_{3} \mathrm{C}-\mathrm{C} \equiv \mathrm{C}-\mathrm{C}\left(\mathrm{SiMe}_{3}\right)_{3} \\
\left(\mathrm{Me}{ }_{3} \mathrm{Si}\right)_{3} \mathrm{C}-\mathrm{C} \equiv \mathrm{C}-\mathrm{C}\left(\mathrm{SiMe}_{3}\right)_{3}\end{array}$ & $\begin{array}{l}40 \\
25\end{array}$ & $\begin{array}{l}\text { Allene (I) }(0-5 \%) \\
\text { Traces of acetylenes, }\end{array}$ \\
\hline $\mathrm{Mg}$ & 0.64 & $\mathrm{Me}_{3} \mathrm{Si}-\mathrm{C} \equiv \mathrm{C}-\mathrm{C} \equiv \mathrm{C}-\mathrm{SiMe}_{3}$ & 44 & $\begin{array}{l}\text { Traces of } 21 \text { other } \\
\text { products }\end{array}$ \\
\hline $\mathrm{Ba}$ & 20 & - & - & Little reaction \\
\hline
\end{tabular}

In a typical experiment hexachlorobutadiene $(0.05$ mole $)$ dissolved in THF is added slowly to lithium $(1.0 \mathrm{~g}$. atom) and chlorotrimethylsilane $(0.5$ mole $)$ in THF. An exothermic reaction occurs immediately with precipitation of lithium chloride. Subsequent work-up gives a 40 per cent yield of the hexakis (trimethylsilyl)but-2-yne (XXI). In some cases about 5 per cent of the allene (I) is also formed as a by-product. Similar experimental procedures were used for sodium and barium; but the work-up is slightly different with magnesium, which gives bis(trimethylsilyl)buta-1,3diyne (XXII) ${ }^{59}$.

As has been found with hexachloropropene, choice of solvent is a pertinent factor in the course of the reaction. Experiments using different solvents have given results essentially similar to those obtained from hexachloropropene, magnesium and chlorotrimethylsilane (Table 7).

In an attempt to learn something of the reaction pattern, lithium and magnesium have been reacted with hexachlorobutadiene in THF solution, followed by addition of chlorotrimethylsilane after removal of excess metal when vapour phase chromatography reveals all the chlorocarbon has been consumed. The same result is obtained with both metals; neither hexakis(trimethylsilyl)but-2-yne (XXI) nor bis(trimethylsilyl)butadiyne (XXII) are formed. Instead, after a vigorous reaction, the main product is a black insoluble carbonaceous-like material. This material does not absorb in the 
HENRY GILMAN et al.

Table 7. Interaction of hexachlorobutadiene with chlorotrimethylsilane and lithium or magnesium in various solvents

\begin{tabular}{|c|c|c|c|c|}
\hline Solvent & Metal & Product & $\begin{array}{c}\text { Yield } \\
\%\end{array}$ & $\begin{array}{c}\text { Other } \\
\text { products }\end{array}$ \\
\hline $\begin{array}{l}\text { 1,2-Dimethoxyethane } \\
\text { Tetrahydropyran } \\
\text { Tetrahydro-2-methyl- } \\
\text { furan } \\
\text { 2,2,4,4-Tetramethyl- } \\
\text { tetrahydrofuran } \\
\text { Diethyl ether } \\
\text { 1,4 Dioxan }\end{array}$ & $\begin{array}{l}\mathrm{Li} \\
\mathrm{Li} \\
\mathrm{Li} \\
\mathrm{Li}, \mathrm{Mg} \\
\mathrm{Li}, \mathrm{Mg} \\
\mathrm{Li}, \mathrm{Mg}\end{array}$ & $\begin{aligned}\left(\mathrm{Me}_{3} \mathrm{Si}\right)_{3} \mathrm{C}-\mathrm{C} & \equiv \mathrm{C}-\mathrm{C}\left(\mathrm{SiMe}_{3}\right)_{3} \\
\left(\mathrm{Me} \mathrm{C}_{3} \mathrm{Si}\right)_{3} \mathrm{C}-\mathrm{C} & \equiv \mathrm{C}-\mathrm{C}\left(\mathrm{SiMe}_{3}\right)_{3} \\
\left(\mathrm{Me}{ }_{3} \mathrm{Si}\right)_{3} \mathrm{C}-\mathrm{C} & \equiv \mathrm{C}-\mathrm{C}\left(\mathrm{SiMe}_{3}\right)_{3} \\
& - \\
& -\end{aligned}$ & $\begin{array}{l}36 \\
24 \\
17 \\
- \\
-\end{array}$ & $\begin{array}{l}\quad- \\
\text { (I) }(11 \%) \\
\text { No reaction } \\
\text { No reaction } \\
\text { No reaction }\end{array}$ \\
\hline
\end{tabular}

infrared region, does not melt at temperatures up to $500^{\circ}$, burns similarly to carbon, and contains only a trace of silicon and chlorine. The formation of this material could be attributed to initial reduction of the hexachlorobutadiene to dichlorobuta-1,3-diyne, which is a very reactive unstable intermediate ${ }^{60}$ and can undergo further transformations in the presence of lithium. The fact that lithium and sodium give rise to an internal acetylene (XXI), whereas magnesium gives reduction to a conjugated acetylene (XXII) is not easy to explain at this stage. A simple interpretation of the formation of XXII from magnesium, chlorotrimethylsilane and hexachlorobutadiene is initial reduction to dichlorobuta-1,3-diyne.

$$
\mathrm{Cl}_{2} \mathrm{C}=\mathrm{CCl}-\mathrm{CCl}=\mathrm{CCl}_{2} \underset{-2 \mathrm{MgCl}_{2}}{\stackrel{2 \mathrm{Mg}}{\longrightarrow}} \mathrm{ClC} \equiv \mathrm{C}-\mathrm{C} \equiv \mathrm{CGl}
$$

This can then react further in one of two ways: (i) attack by magnesium in a Wurtz-Fittig reaction to give XXII: or, (ii) actual formation of the di-Grignard reagent and coupling of the product with chlorotrimethylsilane $\mathrm{e}^{10,11}$ to give XXII. Of course (ii) may provide an explanation of (i).

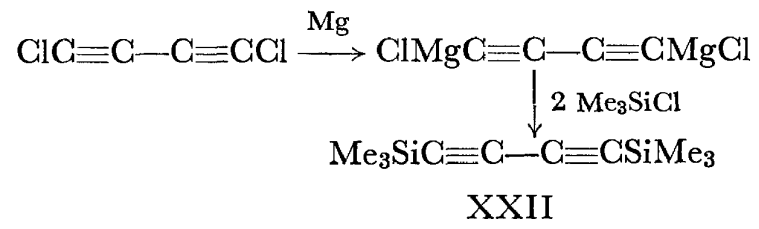

This reaction is essentially similar to that described in the preparation of bis(trimethylsilyl)acetylene from tetrabromoethylene, magnesium and chlorotrimethylsilane ${ }^{8}$.

The formation of the but-2-yne (XXI) is reminiscent of the production of (I) from octachlorohexa-1,3,5-triene which is also a conjugated alkene. It is not easy to decide at which stage of the reaction the rearrangement takes place. Hexachlorobut-2-yne has not been described although the fluorine analogue is well $\mathrm{known}^{61}$. However, under the conditions of the experiment it might be formed to a certain extent and the reaction with trimethyl- 
SILYLATIONS OF SOME POLYHALOGENATED COMPOUNDS

silyllithium (formed transiently from lithium and chlorotrimethylsilane) would give rise to XXI.

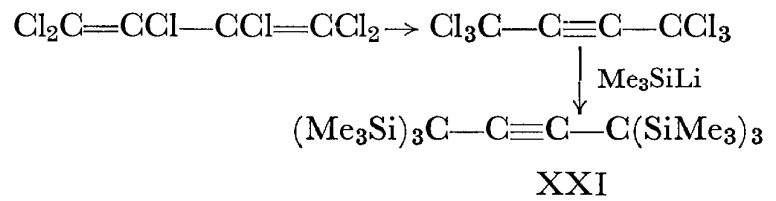

In an alternative scheme, stepwise interaction of trimethylsilyllithium with hexachlorobutadiene could proceed until factors, steric or thermodynamic, favour a rearrangement to a butyne backbone:

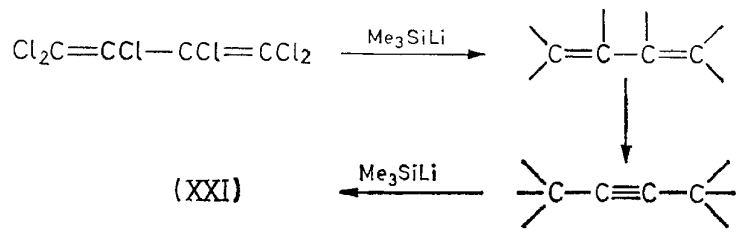

Accompanying the formation of XXI are various amounts (0-5 per cent using THF as solvent, and 11 per cent using tetrahydro-2-methylfuran as solvent) of tetrakis(trimethylsilyl)allene (I). The formation of this compound directly from a 1,3-diene carbon backbone is difficult as such a process would infer rupture of a double bond. It is more likely that at the same stage of the reaction when rearrangement to an internal acetylene occurs, the allene (I) is also formed. We have considered that (I) could be formed from XXI by attack of lithium and chlorotrimethylsilane, but experiments conducted in THF and tetrahydro-2-methylfuran have failed to confirm this. Accordingly (I) must be formed in a side-reaction during the formation of XXI.

Perhaps such a side-reaction involves rearrangement of the 1,3-diene (A) to a 1,2-diene (B) as a step of the conversion to a 2-alkyne.

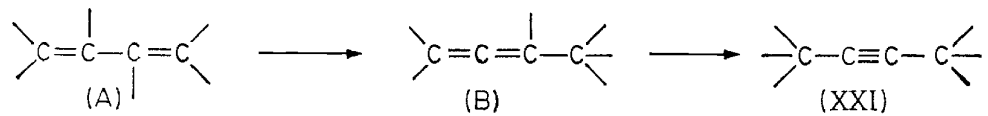

$$
\downarrow c=c=c^{\prime}+\cdot c^{\prime}-
$$

The intermediate species (B) can then be cleaved partially by the attacking reagent at the terminal single bond, to give (I), while most of (B) rearranges to an alkyne and gives rise to (XXI). Unfortunately we have not been able, as yet, to isolate any fragment that could be attributed to the formation of (I) from hexachlorobutadiene, and hence any explanations such as those given above must be recognized as speculative. 


\section{POLYSILYLATIONS OF SOME HIGHLY HALOGENATED HETEROGYGLIG AND MISGELLANEOUS COMPOUNDS}

\section{(i) Reactions producing tetrakis(trimethylsilyl)allene (I)}

In a similar manner to that described previously we have treated pentachloropyridine with lithium (or magnesium) and chlorotrimethylsilane in THF. The reaction produces a large number of compounds, but we have isolated the allene (I) in 10-12 per cent yields with lithium or magnesium at room temperature ${ }^{62}$. The scheme for this reaction is unclear but presumably one can develop similar interpretations to some of those discussed for hexachlorobenzene.

$$
\mathrm{Cl}_{5} \mathrm{C}_{5} \mathrm{~N}-\underset{10 \mathrm{Me}_{3} \mathrm{SiCl}}{20 \mathrm{Li}}(\mathrm{I}) 10-12 \%
$$

The fate of the nitrogen atom is, however, as yet unclear. Not surprisingly, bis(pentachlorophenyl)phenylphosphine and bis(pentafluorophenyl)phenylphosphine also give a detectable quantity of $(\mathbf{I})$, although other products predominate ${ }^{62}$.

\section{(ii) Reactions producing hexakis(trimethylsilyl)but-2-yne (XXI)}

Interest in the production of a pertrimethylsilylated acetylene starting from a perchloro-1,3-diene has prompted us to examine tetrachlorothiophene under similar conditions. The results are very similar to those found with hexachlorobuta-1,3-diene. Using lithium and chlorotrimethylsilane in THF we have obtained a 13 per cent yield of $(\mathrm{XXI})$ whereas with magnesium and chlorotrimethylsilane in THF solution we have detected none of (XXI) although a large number of unidentified products was formed ${ }^{59}$. We are uncertain of the fate of the sulphur atom although we have detected hydrogen sulphide, and organic sulphur compounds are present.

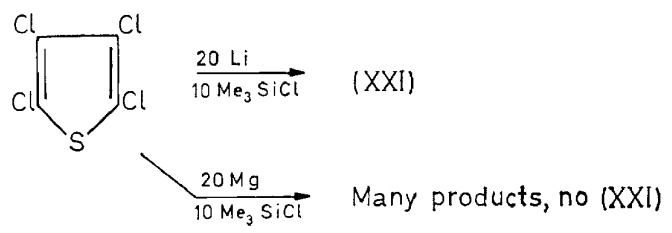

The reaction could proceed by initial attack of the lithium on the heteroatom. The hydrogen sulphide produced on hydrolysis of the reaction mixture could be due to lithium sulphide or hexamethyldisilthian since the $\mathrm{Si}-\mathrm{S}$ bond is readily broken by water ${ }^{63}$. 

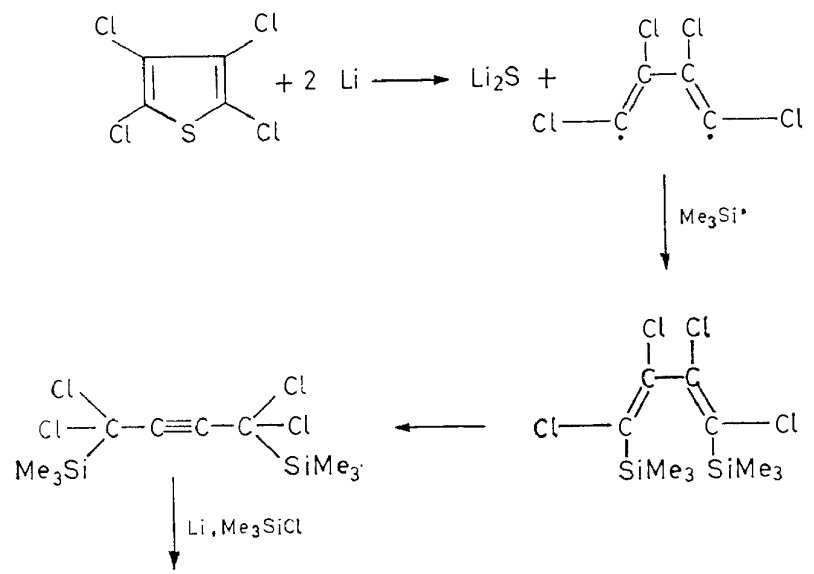

$\left(\mathrm{Me}_{3} \mathrm{Si}\right)_{3} \mathrm{C}-\mathrm{C} \equiv \mathrm{C}-\mathrm{C}\left(\mathrm{SiMe}_{3}\right)_{3}$

(XXI)

In another possible scheme, the ring could remain intact until later stages of the reaction with successive attacks of trimethylsilyllithium upon the chlorine atoms.<smiles>Clc1sc(Cl)c(Cl)c1Cl</smiles><smiles>CSc1c(Cl)sc(Cl)c1Cl</smiles>

\section{PROPERTIES AND SOME CHEMICAL REAGTIONS OF TETRAKIS(TRIMETHYLSILYL)ALLENE (I)}

(a) Physical properties. Colourless oil when freshly distilled; darkens on standing. Boiling point: $69-70^{\circ} / 0 \cdot 2 \mathrm{~mm}$., $119-121^{\circ} / 14 \mathrm{~mm}$., $n_{\mathrm{D}}{ }^{20} 1 \cdot 4770$, $d_{4}{ }^{20} 0.8322$. Infrared, $\mathrm{C}=\mathrm{C}=\mathrm{C}$ absorption at $1880 \mathrm{~cm}^{-1}$.

(b) Chemical properties. The compound appears to have a strong resistance to chemical attack. This may be due in part to a steric effect but also to electronic effects in the allenic system due to the close proximity of trimethylsilyl groups. Some reactions (and non-reactions) are listed in Table 8.

Table 8. Some chemical properties of the allene (I)

\begin{tabular}{|c|c|c|}
\hline Reactant & $\begin{array}{c}\text { Conditions } \\
\text { (Solvent, temperature) }\end{array}$ & Products \\
\hline $\begin{array}{l}\mathrm{Br}_{2} \\
\mathrm{Li}_{1} \mathrm{Me}_{3} \mathrm{SiCl} \\
\text { Hexachlorocyclopentadiene } \\
: \mathrm{CGl}_{2}{ }^{\mathrm{a}} \\
\mathrm{Li}\left[\mathrm{CuMe}_{2}\right]\end{array}$ & $\begin{array}{l}\text { No solvent, } 20^{\circ} \\
\text { THF, } 20^{\circ} \\
\text { No solvent, } 120^{\circ} \\
\text { Hexane, } 0^{\circ} \\
\text { Ether, }-10^{\circ}\end{array}$ & $\begin{array}{l}\mathrm{Me}_{3} \mathrm{SiBr} \\
\text { No reaction } \\
\text { No reaction } \\
\text { No reaction } \\
\text { No reaction }\end{array}$ \\
\hline
\end{tabular}

aFrom $\mathrm{Me}_{8} \mathrm{COK}$ and $\mathrm{CHCl}_{3}$ 


\section{PROPERTIES AND SOME GHEMICAL REACTIONS OF HEXAKIS(TRIMETHYLSILYL)BUT-2-YNE (XXI)}

(a) Physical properties. Melting point $276-277^{\circ}$ (sealed tube); sublimes at $220^{\circ} / 0 \cdot 1 \mathrm{~mm}$. Soluble in pentane, hexane, chloroform, carbon tetrachloride; slightly soluble in acetone, insoluble in methanol and ethanol. Infrared spectrum, no $\mathrm{C} \equiv \mathrm{C}$ absorbance. Raman spectrum, strong band at 2144 $\mathrm{cm}^{-1}$. Stable (sealed tube) to $420^{\circ}$.

(b) Chemical properties. The compound is very inert to normal chemical reagents. This is presumably due in large part to steric hindrance. Such a statement is justified by the relative inertness of the similarly sterically hindered bis( $t$-butyl)acetylene which is not reduced by sodium in liquid ammonia ${ }^{64}$, nor does it react on refluxing with triphenylaluminum for many hours ${ }^{65}$. As an example of the considerable steric hindrance observed in this compound, we have been unable, using models, to construct cis$1,1,1,4,4,4$-hexakis (trimethylsilyl)but-2-ene (XXIII) or trans-1,1,1,4,4,4, hexakis(trimethylsilyl)-2-methylbut-2-ene (XXIV).

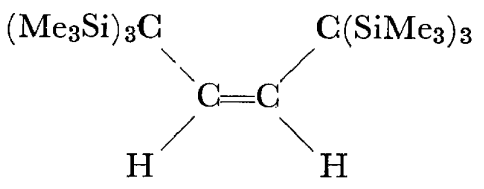

XXIII

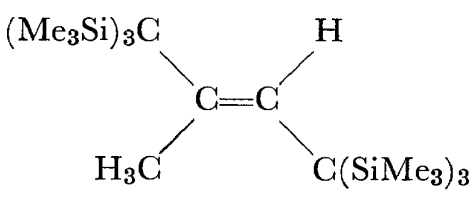

XXIV

However, XXI does react with bromine to give, as one product, bromotrimethylsilane; and with chlorine to give a polymeric product and some hydrogen chloride which may be derived from hydrolysis of $\mathrm{Si}-\mathrm{Cl}$ bonds. Unfortunately, as yet, we have not found XXI to give a reaction characteristic of an acetylenic linkage. The many non-reactions or uncertain reactions are shown in Table 9.

\section{SUMMARY}

Polytrimethylsilylation of polyhalogenated compounds has been investigated. The production of tetrakis(trimethylsilyl)allene from a large number of aliphatic and aromatic polyhalogenated compounds is discussed. The allene is formed in a reaction of the halogeno compound with a liberal excess of lithium or magnesium and a chloroorganosilane. Treatment of polychlorobenzenes with organolithium reagents, followed by derivatization with chlorotrimethylsilane, resulted in the formation of several silylated polyhalobenzenes. Selective halogen-metal or hydrogen-metal interconversion can be achieved by using appropriate organolithium reagents in the lithiation of the polychlorobenzene.

Hexakis(trimethylsilyl)but-2-yne, a highly thermally stable compound which shows a marked resistance to ordinary chemical reactions, has been synthesized from hexachlorobuta-1,3-diene or tetrachlorothiophene, lithium and chlorotrimethylsilane. Closely allied work has been described and pertinent reaction schemes have been postulated. 
Table 9. Summary of some chemical reactions attempted with hexakis(trimethylsilyl) but-2yne $(\mathrm{XXI})$

(a) Addition to Triple Bond

\begin{tabular}{|c|c|c|}
\hline $\begin{array}{l}\text { Reactant } \\
\mathrm{Cl}_{2}\end{array}$ & $\begin{array}{l}\text { Conditions of Reaction } \\
\mathrm{CCl}_{4} \text { solution, } 20^{\circ} \text {, large excess of } \mathrm{Cl}_{2}\end{array}$ & $\begin{array}{l}\text { Products } \\
\text { HCl, unidentified poly- } \\
\text { meric material }\end{array}$ \\
\hline $\mathrm{Br}_{2}$ & $\mathrm{CGl}_{4}$ solution, $20^{\circ} ; \mathrm{Br}_{2}: \mathrm{XXI}=1: 1$ & $\begin{array}{l}\mathrm{Me}_{3} \mathrm{SiBr}, 66 \% \text { unre- } \\
\text { acted XXI }\end{array}$ \\
\hline $\begin{array}{l}\mathrm{HCl} \\
\mathrm{C}_{6} \mathbf{F}_{5} \mathrm{SiMe}_{2} \mathrm{H}\end{array}$ & $\begin{array}{l}\mathrm{C}_{6} \mathrm{H}_{6} \text { solution, } 20^{\circ} ; \text { large excess of } \mathrm{HCl} \\
\mathrm{C}_{6} \mathrm{H}_{6} \text { solution, } 80^{\circ} ; \mathrm{H}_{2} \mathrm{PtCl}_{6} \text { catalyst, } 2 \\
\quad \text { days }\end{array}$ & $\begin{array}{l}\text { No reaction } \\
\text { No reaction }\end{array}$ \\
\hline $\begin{array}{l}\mathrm{C}_{6} \mathrm{H}_{5} \mathrm{Li} \\
\mathrm{Li}\left(\mathrm{Me}_{2} \mathrm{Cu}\right) \\
: \mathrm{CGl}_{2} \text { (from } \\
\left.\mathrm{Me}_{3} \mathrm{COK} / \mathrm{CHCl}_{3}\right)\end{array}$ & $\begin{array}{l}\text { Ether, } 0^{\circ} ; 7 \mathrm{~h} . \\
\text { Ether, }-10^{\circ} ; 12 \mathrm{~h} . \\
\text { Hexane, } 0^{\circ} ; 4 \mathrm{~h} .\end{array}$ & $\begin{array}{l}\text { No reaction } \\
\text { No reaction } \\
\text { No reaction }\end{array}$ \\
\hline $\begin{array}{l}\text { Hydrogenolysis } \\
\mathrm{H}_{2}\end{array}$ & $\begin{array}{l}\text { Cyclohexane, } 200^{\circ} / 50 \mathrm{~atm} \text {; Pd-charcoal } \\
\text { catalyst, } 5 \text { h. }\end{array}$ & No reaction \\
\hline $\mathrm{H}_{2}$ & $\begin{array}{l}\text { Hexane-ethyl acetate }(2: 1) 20 \% \text { atm.; } \\
\text { Pd-CaCO }_{3}\end{array}$ & No reaction \\
\hline Na-liquid $\mathrm{NH}_{3}$ & THF co-solvent & No reaction \\
\hline $\begin{array}{l}\text { Oxidation } \\
\mathrm{SeO}_{2} \\
\mathrm{KMnO}_{4} \\
\mathrm{CrO}_{3}\end{array}$ & $\begin{array}{l}\text { Decalin, } 189^{\circ} ; 4 \mathrm{~h} . \\
\text { Acetone, } 56^{\circ} ; 2 \mathrm{~h} . \\
\text { Acetic acid, } 118^{\circ} ; 7 \mathrm{~h} .\end{array}$ & $\begin{array}{l}\text { No reaction } \\
\text { Little or no reaction } \\
\text { No isolable products, } \\
(30 \% \text { recovered } \\
\text { XXI })\end{array}$ \\
\hline
\end{tabular}

(d) Hydrolysis or Cleazage

\begin{tabular}{|c|c|}
\hline $\mathrm{NaOH}$ & Homogenous and \\
\hline $\mathrm{H}_{2} \mathrm{SO}_{4}$ & $100^{\circ}, 2 \mathrm{~h}$. \\
\hline $\begin{array}{l}\mathrm{Me}_{3} \mathrm{COK}, \mathrm{Me}_{2} \mathrm{SO} \\
\mathrm{Li}, \mathrm{Me} \mathrm{S}_{3} \mathrm{SiCl}\end{array}$ & $\begin{array}{l}\text { Ether } \\
\text { THF and 2-Me-TH }\end{array}$ \\
\hline $\begin{array}{l}\text { Diels-Alder } \\
\text { Hexachlorocyclo- } \\
\text { pentadiene }\end{array}$ & Xylene, $138^{\circ}$; \\
\hline
\end{tabular}

No definite products much recovered XXI No definite products, some recovered XXI No definite products

No reaction

No reaction

This research was supported in part by the United States Air Force under Contract F 33615-68-C-1251 monitored by Materials Laboratory, Wright Air Development Center, Wright-Patterson Air Force Base, Dayton, Ohio. The authors are grateful to Drs. A. G. Brook, J.J. Eisch and R. H. Harrell for assistance and comments, and to Professor $\mathcal{N}$. Carlson for a gift of calcium turnings.

\section{References}

1 W. E. Davidson and M. C. Henry. Chem. Revs. 67, 73 (1967).

2 P. D. George, M. Prober and J. R. Elliot. Chem. Revs. 56, 1065 (1956).

3 C. Eaborn. Organosilicon Compounds, Butterworths Sci. Publ., London, 1960; A. D. Petrov, V. F. Mironov, V. A. Ponomarenko and E. A. Chernyshev, Synthesis of Organosilicon Monomers, Akad. Nauk SSSR, Moscow, 1961; English Translation, Con ultants Bureau, New York, 1964.

4 S. D. Rosenberg, J. J. Walburn, T. D. Stankovich, A. E. Balint and H. E. Ramsden. J. Org. Chem. 22, 1200 (1957).

5 M. Maienthal, M. Hellman, C. P. Haber, L. A. Hymo, S. Carpenter and A. J. Carr. J. Amer. Chem. Soc. 76, 6392 (1954).

6 K. C. Frisch and R. B. Young. J. Amer. Chem. Soc. 74, 4853 (1952); U.S. Pateni, 2,671,099 (1954). 
7 A. D. Petrov, L. L. Shchukovskaya. Doklady Akad. Nauk SSSR. 86, 551 (1952).

8 R. L. Merker and M. J. Scott. J. Amer. Chem. Soc. 85, 2243 (1963).

9 J. G. Billiote and P. Cadiot. Compt. Rend. 251, 730 (1960).

10 B. G. Shakhovski, M. D. Stadnichuk and A. A. Petrov. Zhur. Obshch. Khim. 35, 1714 (1965); J. Gen. Chem. USSR (Engl. Transl.), 35, 1715 (1965).

11 I. A. Shikhiev, M. F. Shostakovskii and L. A. Kayutenko. Dokl. Akad. Nauk Azerb. SSR. 15, 21 (1959).

12 R. Muller and H. Beyer. Chem. Ber. 92, 1957 (1959).

13 H. Gilman and D. Aoki. J. Organometal. Chem. 2, 44 (1964); 2, 293 (1964).

14 R. West, P. A. Carney and I. C. Mineo. J. Amer. Chem. Soc. 87, 3788 (1965).

$15 \mathrm{R}$. West, private communication.

${ }_{16}$ R. L. Merker and M. J. Scott. J. Org. Chem. 29, 953 (1964); J. Organometal. Chem. 4, 98 (1965).

17 C. Tamborski, E. J. Soloski and C. E. Dills. Chem. and Industry 1965, 2067.

18 R. J. Harper, E. J. Soloski and C. Tamborski. J. Org. Chem. 29, 2385 (1964).

19 F. W. G. Fearon and H. Gilman. J. Organometal. Chem. 6, 577 (1966).

${ }^{20}$ H. Gilman and S. Y. Sim. J. Organometal. Chem. 7, 249 (1967).

${ }^{21}$ H. Gilman and K. Shiina. J. Organometal. Chem. 8, 369 (1967).

22 P. J. Morris, F. W. G. Fearon and H. Gilman. J. Organometal. Chem. 9, 427 (1967).

23 F. W. G. Fearon and H. Gilman. J. Organometal. Chem. 10, 409 (1967).

${ }^{24}$ F. W. G. Fearon and H. Gilman. J. Organometal. Chem. 10, 535 (1967).

25 I. Haiduc and H. Gilman. 3rd International Symposium on Organometallic Chemistry, Munich, Aug. 28-Sept. 1, 1967, Abstracts, p. 54.

26 I. Haiduc and H. Gilman. J. Organometal. Chem. 11, 55 (1968).

27 P. J. Morris and H. Gilman. J. Organometal. Chem. 11, $463(1968)$.

${ }^{28}$ K. Shiina, T. Brennan and H. Gilman. J. Organometal. Chem. 11, 471 (1968).

29 I. Haiduc and H. Gilman. J. Organometal. Chem. in press (Parts 21, 24, 25).

${ }^{30} \mathrm{~K}$. Shiina and H. Gilman. J. Amer. Chem. Soc. 88, 5367 (1966).

31 F. W. G. Fearon and H. Gilman. Chem. Comm. 1967, 86.

${ }^{32}$ T. Brennan and H. Gilman. J. Organometal. Chem. 11, 625 (1968).

${ }^{33}$ T. Brennan and H. Gilman. Chem. and Industry. 1967, 1489

${ }_{34}$ T. Brennan and H. Gilman. J. Organometal. Chem. 12, 291 (1968).

35 D. Weyenberg and L. H. Toporcer. J. Amer. Chem. Soc. 84, 2843 (1962); J. Org. Chem. 30, $943(1965)$.

36 A. J. Birch. Quart. Revs. 4, 69 (1950); Austral. J. Chem. 7, 256 (1954); 8, 96 (1955).

37 A. P. Krapcho and A. A. Bothner-By. J. Amer. Chem. Soc. 81, 3658 (1959).

38 R. A. Benkeser, E. M. Kaiser and R. F. Lambert. J. Amer. Chem. Soc. 86, 5272 (1964).

${ }^{39} \mathrm{~K}$. Shiina, T. Brennan and H. Gilman. J. Organometal. Chem. in press.

40 D. D. Gallander, P. L. Coe and J. C. Tatlow. Chem. Comm. 1966, 143.

${ }^{41} \mathrm{H}$. Heaney and J. M. Jablonski. Tetrahedron Letters. 4529 (1966).

42 M. D. Rausch, F. E. Tibbets and H. B. Gordon. J. Organometal. Chem. 5, 493 (1966).

${ }^{42 \mathrm{a}}$. Hengge and N. Holtschmidt. J. Organometal. Chem. 12, P 5 (1968); Monatsch. Chem. 99, 340 (1968).

43 C. Walling. Free Radicals in Solution, J. Wiley, New York, 1957.

44 B. J. McClelland. Chem. Revs. 64, 301 (1964).

45 W. von Doering and P. M. LaFlamme. Tetrahedron, 2, 75 (1958).

${ }^{46}$ L. Skatteböl. Acta Chem. Scand. 17, 1683 (1963); see also, Chem. Ind. 1968, 515.

47 G. Wittig and H. Härle. Liebigs Ann. Chem. 623, 17 (1959).

48 See Ref. 20 and works cited therein.

49 I. Haiduc and H. Gilman. J. Organometal. Chem. 12, 394 (1968).

$50 \mathrm{I}$. Haiduc and H. Gilman. J. Organometal. Chem. in press (Part 29).

51 I. Haiduc and H. Gilman, unpublished results.

52 D. Ballard and H. Gilman. J. Organometal. Chem. 12, 237 (1968).

53 A. Fujino, Y. Nagata and T. Sakan. Bull. Chem. Soc. Japan. 38, 295 (1965).

54 A. Roedig and F. Bischoff. Naturwiss. 49, 448 (1962).

55 A. Roedig, F. Bischoff, B. Heinrich and G. Markl. Liebigs Ann. Chem. 670, 8 (1963).

56 H. J. Prins. Rec. Trav. Chim. 68, 419 (1949).

57 A. Roedig, G. Voss and E. Kuchinke. Liebigs Ann. Chem. 580, 24 (1953).

58 L. M. Kogan. Uspekhi Khim. 33, 396 (1964); Russ. Chem. Revs. (Engl. Transl.), 33, 176 (1964).

59 D. H. Ballard and H. Gilman, unpublished results.

60 F. Strauss, L. Kollek and H. Hauptmann. Chem. Ber. 63, 1886 (1930).

61 A. L. Henne and W. G. Finnegan. J. Amer. Chem. Soc. 71, 298 (1949).

$62 \mathrm{~S}$. S. Dua and H. Gilman, unpublished results.

63 C. Eaborn. J. Chem. Soc. 1950, 3077.

${ }^{64}$ G. F. Hennion and T. F. Banigan. J. Amer. Chem. Soc. 68, 1202 (1946).

${ }^{65} \mathrm{~J}$. J. Eisch, private communication. 